\title{
Reverse-taper lock connection and two-stage body implant treatment: three case reports
}

\author{
Gentaro Mori ${ }^{1}$, Toshikazu Iijima ${ }^{1}$, and Yasutomo Yajima ${ }^{1}$ \\ ${ }^{1}$ Tokyo Dental College
}

July 22,2020

\begin{abstract}
The purpose of this report was to describe the reverse-taper lock connection and two-stage implant treatment. The reverse-taper lock connection was designed to be narrow and strong, the superstructure could be attached by friction force. The two-stage implant allows removal of the infected upper part in the event of peri-implantitis.
\end{abstract}

\section{Key Clinical Message}

The reverse-taper lock connection was designed to be narrow and strong, the superstructure could be attached by friction force without cement and screws The two-stage implant allows removal of the infected upper part in the event of peri-implantitis.

(38 words)

\section{INTRODUCTION}

Dental implant treatment has been clinically used since 1970 in dentistry, and implant design, surface properties, abutment-implant connection style, and superstructure-abutment connection style have evolved over time. Recently, a two- or three-piece implant design has been introduced and demonstrated high survival rates. ${ }^{1}$ However, biological and prosthetic complications have frequently occurred ${ }^{2}$ that require the development of new implant and prosthetic designs that do not induce biological and prosthetic complications. ${ }^{3}$

Generally, superstructure-abutment connection modes are screw fixing and cement fixing. Cement fixation poses a risk of infection due to residual cement, and screw fixation is often selected. Due to the hollow structure of the screw fixation, bacteria invade inside, outside of the component, and the microleakage causes peri-implant bone loss ${ }^{4,5}$ Further, in the case of multiple implant treatments, it takes time to remove all the screws and superstructure, so a connection style that allows easy removal is required. In the past, a method of attaching the superstructure by frictional force has been reported ${ }^{6}$; however, it was difficult to manufacture because custom abutments and electroformed telescopic crowns had to be created. Therefore, a reverse-taper lock system using existing components: a connection system by friction force was proposed. The reverse-taper lock system allows the establishment of new prosthetic designs that do not require cement and screws. This case report describes implant treatment of the reverse-taper lock system and two-stage implant.

\section{CASE 1}

A 42-year-old woman was given one-step-type implant treatment (Figure 1). Although the width of the mandible was narrow, informed consent was obtained for performing implant treatment with a narrow diameter without performing bone graft. We performed two implant placement surgeries, one in the upper jaw and another in the lower jaw. All the surgeries were performed using standard procedures. After 
administering local anesthesia, the mucoperiosteal flap was elevated, and the osteotomy for the implant bed was prepared as per the manufacturer's protocol. All one-step-type implants (Figure 2) (IT-implant; Platon Japan, Co., Ltd., Tokyo, Japan) were inserted using a hand driver at an initial torque of 35 N. Four months after the implant was placed, the implants demonstrated successful osseointegration. Impression was performed using the impression abutment (Platon Japan). Zirconia crown made by a milling machine (DWX-52DC; Roland, Shizuoka, Japan) was luted to the metal frame. The superstructure was created by bonding zirconia to a straight abutment. The superstructure was attached to the abutment by friction force without cement or screws. No mechanical or biological complications including inflammation of the peri-implant soft tissue or resorption of the peri-implant bone (Figure 3,4) were observed during the 4-year follow-up period after fitting.

\section{CASE 2}

A 32-year-old woman received two-step-type implant treatment on the upper anterior teeth region. All twostep-type implants (Figure 5) (IT-implant; Platon Japan) were inserted in parallel direction using Guided Surgery (Straumann AG, Basel, Switzerland) followed by the placement of cover screws on all implants. Four months after implant placement, the implants demonstrated successful osseointegration (Figure 6). Impression was created using the impression abutment (Platon Japan). Intraorally, abutments (Platon Japan) were mounted on the implants; all the abutments were luted to the zirconia frame using resin cement (RelyX Ultimate; 3M ESPE, Seefeld, Germany). A pick-up impression was performed using a VPS impression material (Imprint II; 3M ESPE, Seefeld, Germany) after the resin cement was completely cured. Porcelain was placed on a zirconia frame and baked. The superstructure was attached to the abutment with a reverse-taper lock system without the use of cement or screws. The implant body includes two stages so that if the implant suffers from peri-implantitis, only the infected upper implant body can be removed. At 4 years after the superstructure was placed, no infection or bone resorption was observed (Figure 7,8).

\section{CASE 3}

A 62-year-old woman was administered full-arch implant treatment on the upper jaw. All one-step-type implants (IT-implant; Platon Japan) were inserted in the parallel direction using Guided Surgery (Straumann AG). The metal frame was made from a rigid, nonprecious, cobalt-chromium alloy (Cobatole; IDS, Tokyo, Japan) and intraorally luted abutments to frame with resin cement (RelyX Ultimate). The use of intraorally luted abutments to the frame can compensate for the fit discrepancies of the implant-supported prostheses, allowing the fabrication of retrievable implant-supported prosthesis with minimal strain. Zirconia crown prepared using a milling machine (DWX-52DC; Roland, Shizuoka, Japan) was luted to the metal frame. The superstructure was frictionally connected to the abutment with a reverse-taper lock system without the use of cement or screws (Figure 9). Using an IT crown remover (Platon Japan), the frictional force is released, facilitating an easy superstructure removal (Figure 10,11). No mechanical or biological complications, including inflammation of the peri-implant soft tissue or resorption of the peri-implant bone, were observed during the 4-year follow-up period after the fitting (Figure 12).

\section{DISCUSSION}

In this case report, implant treatment with a new implant-abutment connection mode and two-stage implant treatment were performed, and good results were obtained during the follow-up period. The new connection style attaches the superstructure to friction forces and does not require cement or screws. In addition, as it does not have a hollow structure, there was no microleakage and no marginal bone loss was observed. The two-stage implant design allows the infected area to be removed and a new abutment to be installed if the upper part is infected with bacteria. These new prosthetic designs may offer new implant treatment options.

The reverse-taper lock system boasts a solid implant body with significant mechanical strength. In typical implant, a gap exists between internal and external connections to hold the abutment screw, making the implant body hollow and reducing its strength (Figure 13). In particular, when the implant diameter is thin, the thickness of the implant's inner diameter is also relatively thin, which increases the risk of breaking the implant body. ${ }^{7}$ Conversely, the reverse-taper lock system's mechanical strength is attributable to its lack of a 
hollow structure for the abutment screw. Veneer grafting is performed in cases where the bone width is thin. However, bone transplantation is highly surgically invasive and takes time for the joining of transplanted bones; thus, the treatment period is long and stressful for doctors and patients. In addition, transplanted bone commonly resorbs over time; therefore, a narrow implant with a mechanically strong design is ideal. The reverse-taper lock system is designed for use in implant treatment without bone grafting.

The connection between the implant body and superstructure is maintained by the frictional force of the reverse-taper lock. A precisely manufactured reverse-tapered connection can be gap-free and, therefore, bacteria-resistant. As the reverse-taper lock system is not a hollow structure, it offers the greatest possible security against implant body breakage. Typically, there are two types of abutment-superstructure connection method: screw and cement fixations. Since the screw-fixing method has an access hole, the thickness of the ceramic-veneered material is uneven, and concerns about aesthetics may arise. ${ }^{8}$ When the number of implants is high, the temporary sealant and screw should be removed, requiring enough time to attach and detach the superstructure. In addition, the presence of access holes tends to induce bone resorption via microleakage. This phenomenon is promoted by a gap between implant components that allow the passage of bacteria. Several studies have reported the presence of bacteria outside, between, and within the implant components. ${ }^{4}$ These bacteria and metabolites directly affect the periodontal tissue, causing bleeding, swelling, and odors; in more advanced cases, this can also trigger the development of peri-implantitis and peri-implant bone loss. ${ }^{9}$ Conversely, the cement fixation method is more aesthetic because of not only no access hole but also a risk of infection from the leftover cement. In addition, the superstructure cannot be removed in this context. Therefore, a connection style for the superstructure using the frictional force of a reverse-taper lock was developed. Consequently, the reverse-taper lock system is aesthetic without microleakage and boasts an easy-to-remove implant design. For full arches, the prosthetic retrieval is relatively rapid and easy when using the reverse-taper lock system because it is not fixed with multiple screws, requiring the operator to only release the frictional force using the proprietary crown remover. Among others, this supports advantages in the management of elderly patients, particularly when they are physically debilitated or in care facilities (i.e., nursing homes), as special training of facility personnel is not required.

Implants are always at risk of physiological bone resorption and bone destruction due to peri-implantitis. The longer the elapsed time, the greater the risk of developing peri-implantitis. ${ }^{10,11}$ When using an implant with a moderately rough surface structure, that is, an exposed surface, the biofilm tends to adhere to it and bone resorption induces further inflammation, leading to implant removal. Therefore, to prepare for such infections, an implant design that responds to bone changes is required. The two-step-type implants can be removed when the upper part of the implant body is infected with bacteria due to a unique configuration of the implant body in two stages. The first- and second-stage implant bodies are connected with a torque of $35 \mathrm{~N}$ via a Morse taper connection. In young patients, implant treatments face a longer functioning period, which increases the risk of peri-implantitis. Using a two-stage implant body, responding to changes resulting in peri-implant crestal bone loss is possibly quicker or more effective. After removing the secondstage implant body, the abutment can be re-attached. Two-stage implants have not been clinically studied; therefore, their long-term prognosis is unknown and further research is needed.

\section{CONCLUSION}

The reverse-taper lock is a narrow implant placed in areas that require bone grafting, such as veneer grafts, without actually conducting bone grafting. The implant body of this system is designed to prevent bone resorption by preventing the effects of microgaps and microleakage. The superstructure can be mounted by friction force without screws or cement. In the event of peri-implantitis, the area above the implant body infected with biofilm can be removed, allowing the attachment of a new abutment and superstructure to the remaining part.

\section{AUTHOR CONTRIBUTIONS}

GM conceived the ideas and wrote the paper. GM and TI produced and collected case photos. GM, YY supervised the paper. 


\section{ACKNOWLEDGMENTS \\ CONFLICT OF INTEREST STATEMENT}

The authors deny any conflicts of interest exist in regard to the current study.

\section{REFERENCES}

1. Moraschini V, Poubel LA da C, Ferreira VF, Barboza E dos SP. Evaluation of survival and success rates of dental implants reported in longitudinal studies with a follow-up period of at least 10 years: a systematic review. Int J Oral Maxillofac Surg 2015;44(3):377-388. doi:10.1016/j.ijom.2014.10.023

2. Pjetursson BE, Thoma D, Jung R, Zwahlen M, Zembic A. 2012. A systematic review of the survival and complication rates of implant-supported fixed dental prostheses (FDPs) after a mean observation period of at least 5 years. Clin Oral Implants Res 23:22-38. doi:10.1111/j.1600-0501.2012.02546.x

3. Romanos GE, Delgado-Ruiz R, Sculean A. 2019. Concepts for prevention of complications in implant therapy. Periodontol 2000 81(1):7-17. doi:10.1111/prd.12278

4. Larrucea Verdugo C, Jaramillo Núñez G, Acevedo Avila A, Larrucea San Martín C. 2014. Microleakage of the prosthetic abutment/implant interface with internal and external connection: In vitro study. Clin Oral Implants Res 25(9):1078-1083. doi:10.1111/clr.12217

5. Mericske-stern R. 2014. Internal bacterial colonization of implants : association with peri-implant bone loss Clin Oral Implants Res 957-963. doi:10.1111/clr.12421

6. Mori G, Oda Y, Sakamoto K, Ito T, Yajima Y. 2019. Clinical evaluation of full-arch screw-retained implant-supported fixed prostheses and full-arch telescopic-retained implant-supported fixed prostheses: A 5-12 year follow-up retrospective study. Clin Oral Implants Res 30(3):197-205. doi:10.1111/clr.13406

7. Steinebrunner L, Wolfart S, Ludwig K, Kern M. 2008. Implant-abutment interface design affects fatigue and fracture strength of implants. Clin Oral Implants Res 19(12):1276-1284. doi:10.1111/j.16000501.2008.01581.x

8. Wittneben JG, Millen C, Bragger U. 2014. Clinical performance of screw- versus cement-retained fixed implant-supported reconstructions - a systematic review. Int J Oral Maxillofac Implants 29(Supplement):8498. doi:10.11607/jomi.2014suppl.g2.1

9 Koutouzis T. 2019. Implant-abutment connection as contributing factor to peri-implant diseases. Romanos GE, ed. Periodontol 2000 81(1):152-166. doi:10.1111/prd.12289

10. Adler L, Buhlin K, Jansson L. 2020. Survival and complications: A 9- to 15-year retrospective follow-up of dental implant therapy. J Oral Rehabil 47(1):67-77. doi:10.1111/joor.12866

11. Derks J, Schaller D, Hakansson J, Wennstrom JL, Tomasi C, Berglundh T. 2016. Peri-implantitis - onset and pattern of progression. J Clin Periodontol 43(4):383-388. doi:10.1111/jcpe.12535

\section{FIGURE LEGENDS}

Figure (1) Clinical case, intraoral view at the first visit

Figure (2) Technical drawing of the one-step-type implant

Figure (3) (4) Clinical case after an insertion of the final superstructure. Note the excellent soft and hard tissue responses.

Figure (5) Technical drawing of the two-step implant

Figure (6) Taper lock abutment exposed in the oral cavity

Figure (7)(8) The implant replacing a maxillary anterior tooth. Period of clinical function is 36 months. Note the excellent bone response around the implant and lack of evidence of crestal bone loss. 
Figure (9) On the palate side of the superstructure, a small hole for the superstructure remover is observed Figure (10) For full arches, prosthetic retrieval is relatively rapid and easy because it is not fixed with multiple screws, requiring only release of frictional force using an superstructure remover

Figure (11) The principle of superstructure remover. Using an superstructure remover, the frictional force is released, facilitating an easy superstructure removal.

Figure (12) Full arches of the clinical case

Figure (13) Four different types of abutment connections for implants (from left to right): tapered connection, external hex, internal hex, and reverse-taper lock-type connection

\section{Hosted file}

fig casereport.pdf available at https://authorea.com/users/345279/articles/471537-reversetaper-lock-connection-and-two-stage-body-implant-treatment-three-case-reports 